\section{Commentary: Accepting only over-sized donors for adult congenital heart disease-Is it being overcautious?}

\author{
Yasuhiro Shudo, MD, PhD, and \\ Katsuhide Maeda, MD, PhD
}

Optimal donor size selection to match adult congenital heart disease (ACHD) recipients undergoing orthotopic heart transplant (OHT) has not been fully addressed yet. ${ }^{1}$ In this issue of the Journal, Clark and colleagues ${ }^{2}$ evaluated the impact of donor/recipient size discrepancy on the outcome of patients with ACHD undergoing OHT between 2000 and 2015 using the United Network for Organ Sharing database. The key finding of this study was that donor oversizing did not affect the outcome of this patient cohort, which does not support the prevailing empiric strategy of favorably accepting oversized donors in this patient cohort. Contrastingly, authors mentioned, with an alarm, "such a strategy of empirically oversizing donors may be harmful by the lengthening wait times for transplantation, which has a known correlation with increased mortality."

Furthermore, optimal size matching in heart transplantation is currently a broad topic of interest for many transplant researchers. While the International Society for Heart and Lung Transplantation guidelines recommend that a donor body weight is no more than $30 \%$ less than recipient body weight ( $20 \%$ for female donors) ${ }^{3}$ a recent report indicated that the predicted heart mass (PHM) is a more appropriate parameter. ${ }^{4}$ However, there is no concrete guideline for adult noncongenital heart disease. In this study, the authors employed 5 different metrics to evaluate the donor and recipient size matching, namely, height, body weight, body mass index, left ventricular mass, and PHM. ${ }^{4}$ Among these 5 metrics, the

\footnotetext{
From the Department of Cardiothoracic Surgery, Stanford University School of Medicine, Stanford, Calif.

Disclosures: Authors have nothing to disclose with regard to commercial support.

Received for publication Feb 29, 2020; accepted for publication March 3, 2020; available ahead of print March 19, 2020.

Address for reprints: Katsuhide Maeda, MD, PhD, Department of Cardiothoracic Surgery, Stanford University, 300 Pasteur Dr, Stanford, CA 94305 (E-mail: kmaeda@ stanford.edu).

J Thorac Cardiovasc Surg 2021;162:429-30

$0022-5223 / \$ 36.00$

Copyright (c) 2020 by The American Association for Thoracic Surgery

https://doi.org/10.1016/j.jtcvs.2020.03.029
}

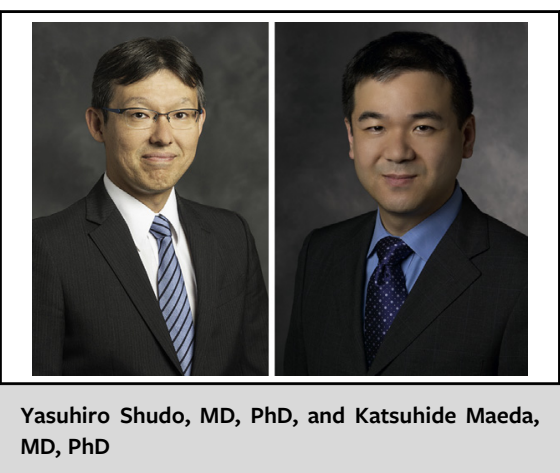

CENTRAL MESSAGE

This report may encourage the expansion of donor pools in selected patients with noncomplex adult congenital heart disease, apart from the strategy of accepting only oversized donors.

results of this study suggest that PHM is the most accurate method for size matching in patients with ACHD, indicating similarities to adult patients with noncongenital heart disease.

Special attention should be paid to some study limitations that may affect the results and generalizability to all patients with ACHD. First, the United Network for Organ Sharing database included some uncollected or missing data. Next, the potential selection bias may be related to beliefs among physicians that some risk factors, such as elevated pulmonary vascular resistance (PVR), are prohibitive risk factors for OHT. Thus, only donors deemed to have acceptable PVR for transplantation were included in this study. Lastly, since the cohort of ACHD has a variety of anatomical subtypes, history of multiple staged operations, and varying degrees of elevated PVR, a detailed subgroup analysis is essential for further studies.

Without the aforementioned data, the reported results should not be immediately applied to the entire spectrum of patients with ACHD. It is still reasonable to follow the philosophy of experts to consider oversized donors for "complex" congenital heart disease, given some concerns for underappreciated elevations in PVR as well as right ventricular-pulmonary artery coupling. Nevertheless, in selected patients with more "simple" congenital heart disease, this report may alter donor and recipient selection, allowing the acceptance of not only oversized donors but 
also size-matched donors. This can potentially shorten the wait times for heart transplant and hopefully reduce the mortality rates for patients on the wait list.

\section{References}

1. Menachem JN, Lindenfield J, Schlendorf K, Shah AS, Bichell DP, Book W, et al. Center volume and post-transplant survival among adults with congenital heart disease. J Heart Lung Transplant. 2018;37:1351-60.
2. Clark DE, Byrne RD, Mazurek JA, Opotowsky AR, Schlendorf KH, Xu M, et al. Sizing heart transplant donors in adult with congenital heart disease. J Thorac Cardiovasc Surg. 2021;162:422-8.e1.

3. Mehra MR, Kobashigawa J, Starling R, Russell S, Uber PA, Parameshwar J, et al. Listing criteria for heart transplantation: International Society for Heart and Lung Transplantation guidelines for the care of cardiac transplant candidates-2006. J Heart Lung Transplant. 2006;25:1024-42.

4. Kransdorf EP, Kittleson MM, Benck LR, Patel JK, Chung JS, Esmailian F, et al. Predicted heart mass is the optimal metric for size match in heart transplantation. J Heart Lung Transplant. 2019;38:156-65.
See Article page 422.

\section{Commentary: One size fits all, maybe}

\author{
Oliver K. Jawitz, MD, and Vignesh Raman, MD
}

In this issue of Journal, Clark and colleagues ${ }^{1}$ examine the association between donor-recipient size matching and post-heart transplant survival among recipients with a history of congenital heart disease (CHD). Overall, the heart transplantation literature has demonstrated poorer outcomes associated with undersizing of donor allografts. ${ }^{2}$ As such, there has been a trend to empirically oversize donor allografts for recipients with CHD, despite a paucity of published data examining the sequelae of donorrecipient size matching in this population. Through a retrospective analysis of the 2000-2015 United Network for Organ Sharing (UNOS) heart transplant registry, Clark and colleagues examined the association between 5 different metrics of size matching and recipient survival among 825 adult patients with CHD. Multivariable Cox proportional hazards modeling adjusted for sex mismatch, candidate pulmonary hypertension, and other factors demonstrated no significant independent association between any of the 5 metrics and recipient survival,

From the Division of Cardiovascular and Thoracic Surgery, Department of Surgery, Duke University Medical Center, Durham, NC.

Dr Jawitz received funding provided by National Institutes of Health (NIH) grant 5T32HL069749. Dr Raman received funding provided by NIH grant 5T32CA093245.

Disclosures: Authors have nothing to disclose with regard to commercial support.

Received for publication March 10, 2020; revisions received March 10, 2020; accepted for publication March 12, 2020; available ahead of print April 5, 2020.

Address for reprints: Oliver K. Jawitz, MD, Department of Surgery, Duke University School of Medicine, Duke Clinical Research Institute, Box 3850, 200 Morris St, Durham, NC 27701 (E-mail: oliver.jawitz@duke.edu).

J Thorac Cardiovasc Surg 2021;162:430-1

$0022-5223 / \$ 36.00$

Copyright $(\odot 2020$ by The American Association for Thoracic Surgery

https://doi.org/10.1016/j.jtcvs.2020.03.114
Check for updates

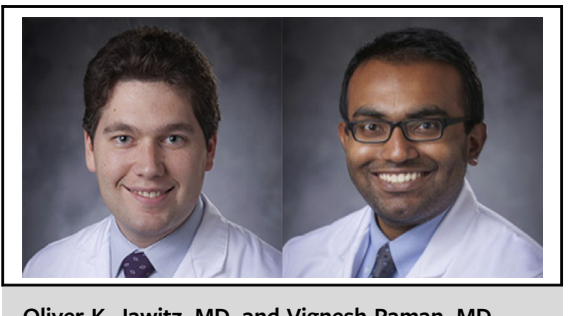

Oliver K. Jawitz, MD, and Vignesh Raman, MD

CENTRAL MESSAGE

Donor-recipient size matching may be less important for CHD patients undergoing heart transplant, although there are a number of important limitations to consider before modifying clinical practice.

suggesting that perhaps donor-recipient size matching is less important when transplanting patients with CHD.

When considering new evidence to potentially modify clinical practice, it is vital that we closely examine the limitations of that evidence as well as its generalizability to our patient population. As the authors point out in several locations throughout their manuscript, conclusions drawn from retrospective reviews of registry data can be significantly impacted by selection bias. In the case of this analysis, selection bias is likely multifactorial, related to both the recipients who were deemed suitable for transplant as well as the degree to which size matching influenced decisions regarding allograft acceptance. Indeed, less than $6 \%$ of all recipients studied were categorized as "undersized," and these recipients likely 